\title{
Public Acceptance of Driverless Buses in China: An Empirical Analysis Based on an Extended UTAUT Model
}

\author{
Jian Chen $\mathbb{D}^{1},{ }^{1}$ Rui Li $\mathbb{D}^{1},{ }^{1}$ Mi Gan $\mathbb{D}^{2},{ }^{2}$ Zhiyan Fu, ${ }^{3}$ and Fatao Yuan ${ }^{1}$ \\ ${ }^{1}$ College of Traffic and Transportation, Chongqing Jiaotong University, Chongqing 400074, China \\ ${ }^{2}$ School of Transportation and Logistics, Southwest Jiaotong University, Chengdu, Sichuan 610031, China \\ ${ }^{3}$ School of Economics and Business Administration, Chongqing University of Education, Chongqing 400067, China \\ Correspondence should be addressed to Mi Gan; migan@swjtu.edu.cn
}

Received 5 August 2020; Revised 17 October 2020; Accepted 25 October 2020; Published 11 November 2020

Academic Editor: Tingsong Wang

Copyright (C) 2020 Jian Chen et al. This is an open access article distributed under the Creative Commons Attribution License, which permits unrestricted use, distribution, and reproduction in any medium, provided the original work is properly cited.

Driverless buses are expected to play a vital role in the future, and better public acceptance will provide a social foundation for its development. In this study, two new variables, personal innovativeness (PI) and perceived risk (PR), were incorporated into the integrated technology acceptance model (UTAUT, unified theory of acceptance and use of technology) to construct an extended model, which was then applied to explore the influencing factors for the public acceptance of driverless buses. The quality of this extended model was verified through survey data collected in Chongqing, China. The structural equation modeling (SEM) method was adopted to quantitatively describe the impact of each factor on acceptance intention (AI) as well as the mutual influence relationships between the factors. The moderating effects of demographic attributes (gender, age, and education level) on each factor in the model were also analyzed. The results showed that PI and PR are the most critical factors that affect the public's acceptance intention; effort expectancy (EE), performance expectancy (PE), social influence (SI), and facilitating condition (FC) can also determine the acceptance intention to a certain extent; gender, age, and education level have exhibited significantly different moderating effects on the influencing factors. The explanatory power of the current research model for acceptance intention has reached $48 \%$. This study has confirmed the applicability of the extended UTAUT model to the research of driverless bus acceptance and the research outcomes can serve as a reference basis for improving the service quality of driverless buses in China.

\section{Introduction}

Autonomous or self-driving technology has received unprecedented attention since its inception. At present, as the relevant technology development is becoming mature, autonomous vehicles (AVs) are gradually coming out of the laboratory and making their debut in the market. This will bring brand-new travel experiences to consumers and alter future traffic patterns. The American Society of Automotive Engineers (SAE) classifies AVs into six levels according to their level of automation [1]; among them, Level 5 (full driving automation) represents the true "unmanned driving." The autonomous driving technology can be expected to effectively reduce traffic accidents caused by fatigued drivers and other violation behaviors, alleviate traffic congestion resulting from differences in driving behaviors, and reduce fuel consumption through optimal trajectory planning and automatic operations [2].

Major automobile and Internet companies worldwide (such as Tesla, EasyMile, Google, and IBM) are now racing to deploy autonomous driving technology and striving to influence the transportation industry. Nevertheless, the urban public transportation field-where the operating lines are relatively fixed, and the road traffic conditions are relatively regular-may be given priority for applying autonomous driving technology. The driverless bus is a new type of intelligent bus that can learn the surrounding road environment through numerous on-board sensors, as well as automatically control the vehicle steering and driving speed through the automated driving system. Road tests of 
driverless buses have already been initiated in many countries, such as Olli launched jointly by IBM and Local Motors (a vehicle manufacturing company) in the United States (USA), EZ10 developed by EasyMile, Arma from Navya in France, and the Alphabus in Shenzhen, and Baidu's Apolong in China. However, due to the comprehensiveness and complexity of transportation systems, there are still many constraints for officially launching large-scale operations of driverless public transportation to the public. Such constraints are mainly manifested in terms of software technology, regulatory mechanisms, and public acceptance. A series of accidents-such as the world's first AV-related fatal accident during a highway collision of a Tesla Model S in 2016, the collision between a Navya driverless bus and a truck in 2017, and the death of a pedestrian caused by one of the Uber's driverless vehicles in 2018-have triggered the public to question the technology readiness level (TRL) of autonomous driving and the regulatory system.

In addition to the inherent technical reasons, public acceptance is also a factor that affects the official introduction and application of autonomous driving technology in the market $[3,4]$. In recent years, many scholars have investigated public acceptance for autonomous vehicles. Schoettle and Sivak [5] conducted a public opinion survey based on 1,533 respondents from the USA, the United Kingdom, and Australia; most of the respondents expressed a reluctance to pay additional fees for the autonomous driving technology. Kyriakidis et al. [6] surveyed 4,886 respondents in 109 countries or regions and revealed that fully automated driving is more acceptable than manual driving, but respondents are particularly concerned about software abuse by hackers, legal issues, and security problems. Tennant et al. [7] surveyed 11,827 drivers in 11 European countries and regions; they found that the respondents' acceptances are correlated with their optimism as well as knowledge of autonomous driving technology. Other studies have pointed out the acceptance of autonomous driving technology is significantly affected by demographic attributes (such as age, gender, and education level) as well as personality heterogeneity [8-10].

Many projects of autonomous driving technology in the public transportation sector (such as EUREF in Berlin, Germany; CityMobil2 funded by the European Union (EU); and SmartShuttle in Switzerland) are in the process of performing acceptance assessments. The questionnaire study by Nordhoff et al. [11] found that the functional design (such as spaciousness and comfort) of automated shuttles and the service characteristics (such as travel cost, time en route, and waiting time) are the key factors influencing public acceptance. The study of Salonen et al. [12] points out that Finnish respondents of different ages, genders, and education levels have significantly different subjective perceptions of traffic safety, in-vehicle security, and emergency management in driverless shuttle buses. Bernhard et al. [13] conducted a survey in Mainz, Germany, and found that public acceptance of ElektroMobilität Mainz Autonom (EMMA) is mainly affected by ease of using the buses and performance expectancy of the buses.
Although many studies have begun to investigate the acceptance of autonomous driving technology, the influencing factors being considered in these studies are still limited. Some of the psychological determinants of public acceptance remain unclear, and the psychological decisionmaking process of the public cannot be described comprehensively. There are some studies on the acceptance of autonomous driving in China [4, 14-16]; however, the research is still in its infancy, and there are few studies on the acceptance of driverless buses. Thus, in this study, the driverless bus is the research object, and a corresponding acceptance analysis model is established to quantitatively describe the public's psychological feelings about driverless buses and to reveal the influence mechanism of various factors on the acceptance intention (AI). The research outcomes are expected to provide decision-making references for technical developers, policymakers, and operations managers of driverless buses in China, thereby facilitating the ability to provide better products and service quality.

The rest of this paper is organized as follows: in Section 2, the research hypotheses of this study are proposed after reviewing the literature related to autonomous driving technology; in Section 3, the research survey design, variable measurement, and data analysis methods are introduced; in Section 4, the data analysis results of the research model are presented; in Section 5, the impacts of model variables on the acceptance intention of driverless buses are compared and analyzed against the research findings of other studies; in Section 6, the theoretical and practical significance of this study is summarized and the limitations of the current study and the future research directions are also noted.

\section{Literature Review and Research Hypothesis}

2.1. Previous Theoretical Model Research. In sociology and psychology research, many theoretical models have been developed to analyze and explain the public acceptance of a certain technology. The most widely used models are technology acceptance model (TAM) and unified theory of acceptance and use of technology (UTAUT). In 1989, Davis proposed TAM while studying the acceptance of information systems; he argued that behavioral intention (BI) plays an important role in affecting people's actual use behavior (UB), and BI is influenced by the combined effect of three determinant factors, namely, perceived usefulness (PU), perceived ease of use (PEOU), and attitude toward using (ATU) [17]. The corresponding model framework is illustrated in Figure 1(a). PU in the model reflects the degree to which an individual believes that using the information system would enhance his/her job performance; PEOU reflects the degree of ease/difficulty an individual believes is involved in using the information system; ATU refers to the positive or negative subjective feeling of an individual when using the information system. The TAM adopted the theory of reasoned action (TRA) [19] and theory of planned behavior (TPB) [20] as the theoretical basis and applied the behavioral theories to the field of technology acceptance research for the first time. Some variables in the model (such as attitude, use intention, and UB) are along the same line as 


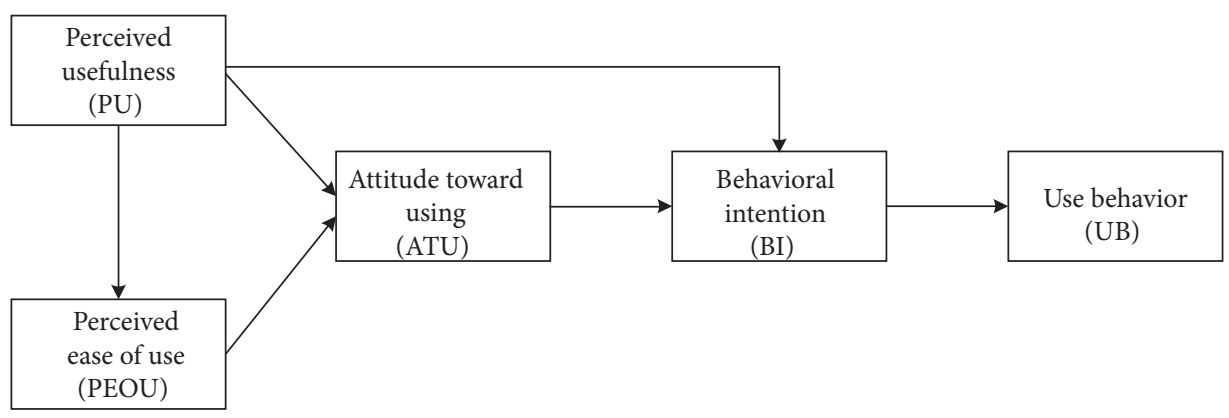

(a)

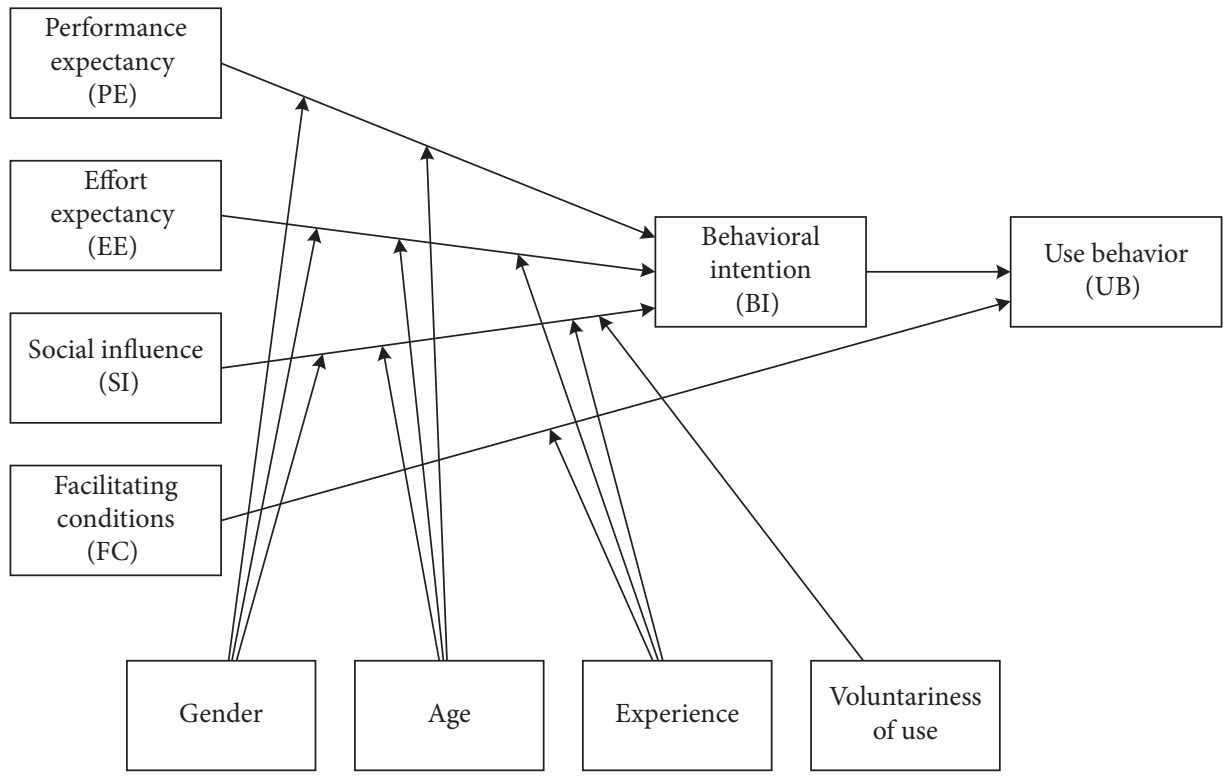

(b)

FIgURE 1: (a) Original TAM proposed in Davis [17]. (b) Original UTAUT proposed in Venkatesh et al. [18].

TRA and TPB; also, external factors-such as system design features, user characteristics, and policy environment-are permitted to impose a moderating effect on model variables [21]. There have been many studies that applied TAM to the research field of acceptance for AVs or automated road transportation systems (ARTS). However, researchers have gradually noticed that the influencing factors for acceptance intention are not only limited to the typical PU and PEOU in TAM, but also include trust, perceived risk (PR), social influence (SI) $[16,22,23]$ and hedonic motivation (HM), psychological ownership, personality traits, and external environment [24-26]. Therefore, researchers have extended the original TAM by incorporating these new variables, the impacts of which on the acceptance behaviors have also been confirmed through investigations and research.

In order to further extend the influencing factors for acceptance of information systems and enhance the explanatory power of the model, Venkatesh et al. [18] proposed an integrated technology acceptance model (UTAUT) by combining eight behavioral theories, including TRA, TRB, diffusion of innovations (DIT) theory, social cognitive theory, and others. The UTAUT model regards effort expectancy (EE), performance expectancy (PE), SI, and facilitating condition (FC) as the core variables and considers that gender, age, experience, and voluntariness of use (VOU) have significant moderating effects on these core variables. The model framework is illustrated in Figure 1(b). The UTAUT model is a powerful theoretical tool for predicting and explaining the acceptance of information technology by individuals or organizations. It has been widely applied in research of social behavior, learning behavior, business behavior, and many other fields [27-31]. However, because its initial variables are mainly designed to study the acceptance of information systems, it has certain limitations for research in other fields. Therefore, it is usually necessary to incorporate new variables-that can reflect the characteristics of the research object-to extend and improve the UTAUT model, thereby enhancing its explanatory power. The most representative application of the UTAUT model in the research field of acceptance for ARTS is the study by Madigan et al. At first, they used the original UTAUT model to explore the impacts of the existing variables on the acceptance of ARTS in the CityMobil2 project [32]; then, in a later study, they added a new variable HM to the original model [33]. Their studies found that EE, PE, SI, FC, and HM all have a significant impact on acceptance 
intention, but the explanatory power of their model needs further improvement. Rahman et al. [34] applied the UTAUT framework to investigate the acceptance intentions of American drivers for advanced driver assistance systems (ADAS) and pointed out that PE has the greatest impact on acceptance intention compared to other variables. Based on UTAUT, Kaur and Rampersad [35] discussed the impacts of trust, PE, safety, reliability, and other factors on the acceptance of driverless cars for Australian respondents. In a study of acceptance for driverless buses, Bernhard et al. [13] initiated an intention survey on an autonomous minibus, EMMA, in Mainz, Germany, and found that PE in the UTAUT model is an important predictor of acceptance intention, while the role of $\mathrm{EE}$ is less effective.

Recent studies that have applied TAM or UTAUT to explore the public acceptance of autonomous driving are summarized in Table 1. The literature review showed that the applications of TAM and UTAUT in the research of the acceptance behavior for autonomous driving technology are still in the early development stage. Researchers are constantly exploring new influencing factors to extend the TAM or UTAUT model and thereby better analyze the psychological decision-making process of the acceptance behavior for autonomous driving technology. The adopted research methods include descriptive statistics, multiple regression analysis (MRA), and structural equation modeling (SEM). In addition, it has been confirmed that UTAUT has a stronger explanatory power than TAM [18]. Therefore, this study aims to extend the UTAUT framework to explore the public acceptance of driverless buses in China.

2.2. Research Hypothesis. To better explain the public acceptance intention for driverless buses and explore the corresponding influencing factors, a UTAUT-based acceptance analysis model for driverless buses is established in this study. In this model, the five variables of AI, EE, PE, SI, and FC are from the original UTAUT model, while the other two variables of personal innovativeness (PI) and perceived risk (PR) are newly added in the current study after referring to relevant theories, to enhance the applicability of UTAUT model for the analysis of public acceptance intention for driverless buses. The research hypothesis and overall architecture of the model is illustrated in Figure 2.

2.2.1. Acceptance Intention (AI). The idea of using $\mathrm{BI}$ to reflect actual behaviors originated from the TRA and TPB theories. In later TAMs, this idea continues to apply, and its effectiveness has been extensively studied and demonstrated. In the UTAUT model, BI is usually used as the dependent variable of influencing factors for the research [17, 36]. Acceptance intention is a BI that reflects the willingness of people to accept driverless buses. Therefore, acceptance intention can be used as the dependent variable of each influencing factor in the study to explore public acceptance. their definitions are similar to those by Venkatesh et al. EE here refers to the public's subjective feelings about the ease/ difficulty of using driverless bus services or the degree of effort. The public believes that the more accessible the facilities and equipment of driverless buses are, and the easier the system is to use, their acceptance intentions will be more positive. PE here refers to the public's subjective feelings about the level of satisfaction of their traveling requirements, the degree of enhancement of their work efficiency, and the level of improvement in their life quality when using driverless buses. The stronger these subjective feelings are, the more likely the public will accept driverless buses. Moreover, many studies have agreed that both $\mathrm{EE}$ and $\mathrm{PE}$ have a positive impact on BI $[18,33]$. Therefore, the following hypotheses are formulated:

H1: EE has a positive impact on the public's acceptance intention of driverless buses

$\mathrm{H} 2$ : PE has a positive impact on the public's acceptance intention of driverless buses

2.2.3. Social Influence (SI) and Facilitating Conditions (FC). SI refers to the degree to which the public's personal thoughts, cognitions, and behaviors are influenced by social groups (family, friends, colleagues, etc.) in their living environment. Similar to the concept of subjective norm in TRA, TPB, and TAM [18-20], the acceptance intention of driverless public transportation by the surrounding social groups will directly affect an individual's acceptance intention. In some studies, SI has already been explored as an influencing factor for the acceptance intention of autonomous driving technology [23, 25, 37]. FC represents the extent to which existing organizations or infrastructures have promoted the development of driverless public transportation. They are mainly used to characterize the impacts of external environmental factors, such as management policies that promote the use intention. FC was initially used to examine employees' use intentions of personal computers [38]. After the empirical research by Venkatesh, it was incorporated into the UTAUT model as an important influencing factor in the research field of technology acceptance. According to the roles of these two variables in the UTAUT model, the following hypotheses are formulated:

H3: SI has a positive impact on the public's acceptance intention of driverless buses

H4: FC has a positive impact on the public's acceptance intention of driverless buses

2.2.4. Personal Innovativeness (PI) and Perceived Risk (PR). The concept of PI originates from the DIT theory [39]. It describes personality traits; more specifically, here it refers to the personal interest in and acceptance of innovative technologies. Individuals with stronger PI tend to have higher expectations for the applicability of emerging technologies and also pay closer attention to the innovative development of technologies. They often aspire to stay ahead 
TABLE 1: Research exploring the public acceptance of autonomous driving technology using the TAM or UTAUT model.

\begin{tabular}{|c|c|c|c|c|c|}
\hline Lead Author (year) & Country & $\begin{array}{c}\text { Theoretical } \\
\text { model }\end{array}$ & Analytical method & Main influencing factors & References \\
\hline Choi (2015) & Korea & TAM & $\begin{array}{c}\text { Partial least-squares } \\
\text { (PLS) regression analysis }\end{array}$ & Trust, PEOU & Choi and Ji [22] \\
\hline Madigan (2016) & $\begin{array}{l}\text { France and } \\
\text { Switzerland }\end{array}$ & UTAUT & MRA & EE, PE, SI & Madigan et al. [32] \\
\hline Madigan (2017) & Greece & UTAUT & MRA & PE, SI, FC, HM & Madigan et al. [33] \\
\hline Rahman (2017) & USA & UTAUT & $\begin{array}{l}\text { Confirmatory factor } \\
\text { analysis (CFA) }\end{array}$ & $\mathrm{EE}, \mathrm{PE}$ & Rahman et al. [34] \\
\hline Winter (2018) & USA & TAM & Descriptive statistics & $\begin{array}{c}\text { Personality traits, external } \\
\text { environment }\end{array}$ & Winter et al. [24] \\
\hline Kaur (2018) & Australia & UTAUT & SEM & $\mathrm{PE}$, trust, reliability & Kaur and Rampersad [35] \\
\hline $\begin{array}{l}\text { Panagiotopoulos } \\
\text { (2018) }\end{array}$ & Greece & TAM & MRA & Perceived trust, SI & $\begin{array}{l}\text { Panagiotopoulos and } \\
\text { Dimitrakopoulos [25] }\end{array}$ \\
\hline Lee et al., 2019 & Korea & TAM & SEM & $\begin{array}{l}\text { PR, self-efficacy, } \\
\text { psychological ownership }\end{array}$ & Lee et al. [26] \\
\hline Zhang (2019) & China & TAM & SEM & Initial trust, $\mathrm{PR}$ & Zhang et al. [16] \\
\hline Zhang (2020) & China & TAM & SEM & Initial trust, SI & Zhang et al. [23] \\
\hline Bernhard (2020) & Austria & UTAUT & SEM & $\begin{array}{c}\text { EE, PE, environmental } \\
\text { awareness, use experience }\end{array}$ & Bernhard et al. [13] \\
\hline
\end{tabular}

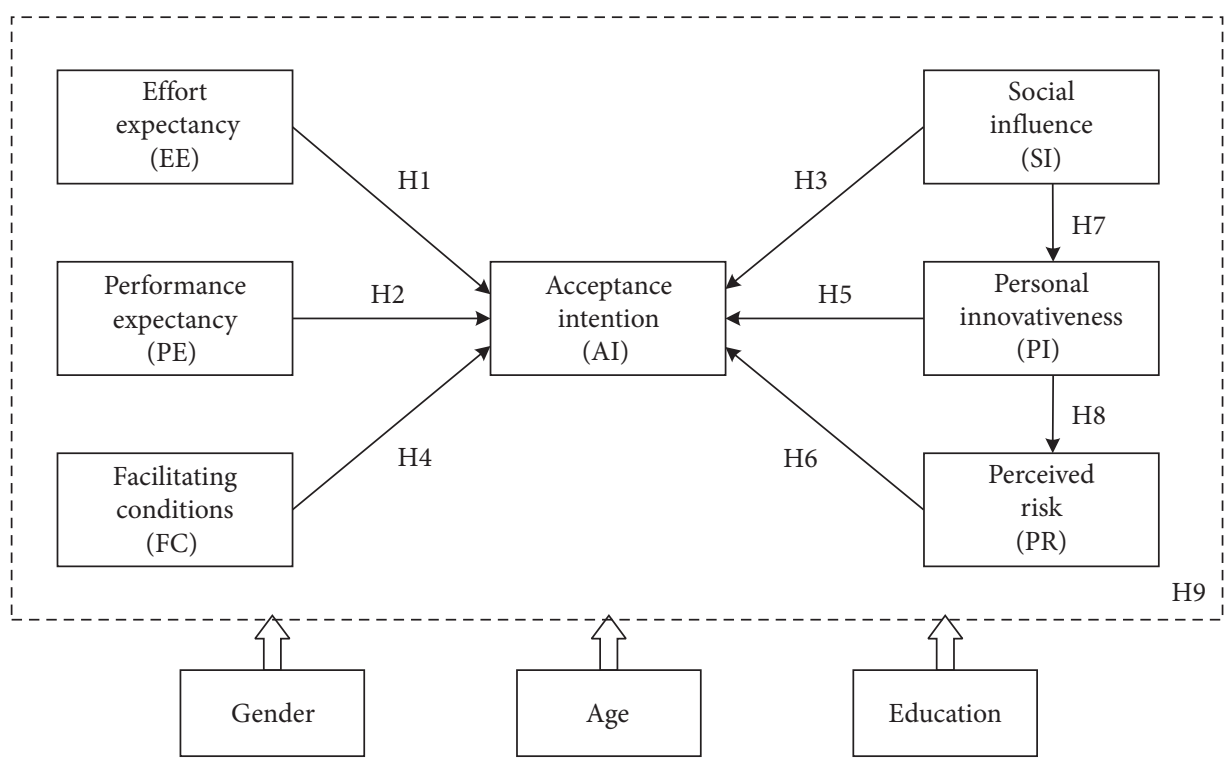

FIGURE 2: Research hypothesis and overall architecture of the model.

of their peers and act as the earliest adopters of the latest products. PI can also trigger continuous personal attention to emerging technologies, thereby affecting their acceptance intention. The higher the PI is, the stronger the acceptance intention will be for emerging technologies.

PR refers to an individual's perceived uncertainty about the outcome of a decision [40]. Some studies have further subdivided PR into the six aspects of time risk, financial risk, functional risk, physical risk, psychological risk, and social risk [41]. PR has also found preliminary applications in the research field of technology acceptance for autonomous driving $[14,42]$. In this study, it is believed that PR has a direct impact on the acceptance of emerging driverless bus technology. When individuals are exposed to emerging technologies, they may assess the potential risks subconsciously. If the PR reaches a certain level, it will result in a negative acceptance intention; on the contrary, if an individual feels that the technology is safe and reliable, he/she will be more willing to accept and use it.

In addition, we believe that the innovation behavior and consciousness of relatives and friends of an individual will stimulate the development of his/her innovative thinking; that is, SI can have a positive impact on PI. Also, a person with stronger PI will possess more courage to try new things and assume corresponding risks and thereby unconsciously ignore potential risks, resulting in a relatively low PR level. Therefore, the following hypotheses are formulated: 
H5: PI has a positive impact on the public's acceptance intention of driverless buses

H6: PR has a negative impact on the public's acceptance intention of driverless buses

H7: SI has a positive impact on PI

H8: PI has a negative impact on PR

2.2.5. Controlled Variables. In a use intention study of information technology, Venkatesh et al. analyzed the moderating effects of personal attributes-such as age, gender, experience, and VoU-on the core variables in the UTAUT model [18]. The driverless bus is an emerging technology, and relevant use experience is still lacking; also, the public has sufficient freedom to determine their acceptance of the technology, and there is no forced acceptance due to pressure from the government or organizations at the moment. Therefore, the effects of experience and VoU on the model are not addressed in the current study. Additionally, considering that individuals with higher education levels may have a better understanding of the pros and cons of driverless buses, they could be more likely to accept the technology. To explore whether personal attribute variables (age, gender, and education level) have significantly different effects on the acceptance intention of driverless buses, the following hypothesis is formulated:

H9: there are significant differences in the effects of controlled variables-such as age, gender, and education level-on the core variables of the model

\section{Methods}

3.1. Survey Design. Chongqing is the third demonstration zone of smart vehicles and intelligent transport, but also one of the first cities to carry out road testing for autonomous driving in China. Its automobile industry (the city's pillar industry) has certain advantages throughout the country. In addition, compared with other cities, Chongqing's road traffic situation is more complicated, and the traffic behavior of citizens is more special because Chongqing is a typical mountainous city. Therefore, exploring the public acceptance of autonomous driving or unmanned driving in Chongqing has a certain representative. In this study, residents of Chongqing were selected as the survey object, and a combination of online and offline questionnaires was distributed to investigate the public acceptance intention of driverless buses. A brief textual introduction of the driverless bus was given at the beginning of the questionnaires in the survey, accompanied by relevant pictures of its appearance, internal space, and actual operating status. The online survey also included related operating videos of driverless buses. This was expected to create a more intuitive feeling of driverless buses for the respondents and increase their understanding of the item descriptions in the questionnaires. And the survey contained two parts: the first part gathered the demographic characteristics, including gender, age, and education level; the second part was a measurement scale for the public's subjective perceptions of driverless buses, covering the measurement of seven variables, namely, EE, PE, SI, FC, PI, PR, and AI. The measurement scales used in the past research of technology acceptance were analyzed and adapted accordingly, so as to obtain the measured scale applicable for this study. Based on the designed measurement scale, the reliability and validity of the questionnaires were examined by the data collected through a small sample pretest. The measurement items that failed in the test were removed to obtain the final and formal questionnaires. After testing, it took approximately 5 to 10 minutes to complete one questionnaire.

The survey was conducted in August 2019 and October 2020 in Chongqing, where 1000 copies of the formal questionnaire were issued within two weeks totally. After eliminating invalid questionnaires-that were not filled in carefully, had more than three missing values, and selected more than five extreme values consecutively-a total of 913 valid questionnaires were recovered, with an effective recovery rate of $91.30 \%$. The number of online and offline questionnaires was 262 and 651, respectively, with a ratio of approximately $1.0: 2.5$. The number of valid samples was more than ten times the number of questions in the questionnaire (26 questions), which conforms to the empirical criteria proposed by Hoogland and Boomsma as well as Kline [43, 44], and it was sufficient in terms of theoretical research and could be used to verify the theoretical model. The basic information of the recovered 913 valid questionnaires was categorized, and the specific personal attributes data are detailed in Table 2. In order to ensure that the influence of control variables (gender, age, and education level) on the acceptance intention is not interfered by the diversity of samples, this survey intentionally controlled the selection of respondents and the sampling area in the process of offline questionnaires distribution, so as to make the total number of samples was evenly distributed in age, gender, and education level.

3.2. Research Measurement. The 7-point Likert scale was adopted in this study to measure the latent variables that cannot be directly observed in the model. A 7-point score-from "strongly disagree $(=1)$ " to "strongly agree $(=7)$ " - was used to rank the respondent's degree of approval towards the relevant description given in each questionnaire measurement item, so as to reflect the public's psychological feelings about driverless buses. The measurement items for each variable were adapted accordingly based on previous research in the field of technology acceptance, mainly from Davis [17], Venkatesh et al. [18], and Thompson et al. [38]. The specific measurement items are detailed in Table 3.

3.3. Data Analysis. To simultaneously explore the influence relationships between latent variables-that are relatively abstract in concept and cannot be measured directly-the method of SEM, a multivariate statistical analysis technique, was applied to analyze the data. SEM can be divided into measurement modeling (MM) and structural modeling (SM), where MM is used to describe the relationship between the observable variables and the latent variables, and 
TABle 2: Description of questionnaire statistics $(N=913)$.

\begin{tabular}{lccc}
\hline Personal attribute & Classification & Sample size $(N)$ & Percentage $(\%)$ \\
\hline \multirow{2}{*}{ Gender } & Male & 468 & 51.24 \\
& Female & 445 & 48.76 \\
\hline \multirow{2}{*}{ Age (years) } & $<18$ & 167 & 18.27 \\
& $18-25$ & 198 & 21.68 \\
& $26-40$ & 184 & 20.15 \\
& $41-60$ & 185 & 20.31 \\
Education level & $>60$ & 218 & 19.59 \\
& High school and below & 235 & 23.87 \\
& College degree & 242 & 25.73 \\
& Bachelor's degree & 218 & 26.49 \\
\end{tabular}

TABle 3: Measurement items for model variables.

\begin{tabular}{|c|c|c|c|}
\hline $\begin{array}{l}\text { Latent } \\
\text { variable }\end{array}$ & $\begin{array}{c}\text { Item } \\
\text { no. }\end{array}$ & Measurement item & Adapted source/reference \\
\hline $\mathrm{EE}$ & $\begin{array}{l}\text { EE1 } \\
\text { EE2 } \\
\text { EE3 }\end{array}$ & $\begin{array}{l}\text { Test ride locations for driverless buses will be easy to find } \\
\text { The payment methods for taking driverless buses will be straightforward } \\
\text { I will soon become familiar with and accustomed to taking driverless buses }\end{array}$ & Venkatesh et al. [18] \\
\hline PE & $\begin{array}{l}\text { PE1 } \\
\text { PE2 } \\
\text { PE3 }\end{array}$ & $\begin{array}{l}\text { Driverless buses can reduce traffic congestion, thereby shortening the riding time } \\
\text { Driverless buses can reduce traffic accidents } \\
\text { Driverless buses can improve the efficiency and quality of my study, work, and life }\end{array}$ & $\begin{array}{c}\text { Davis [17] and Venkatesh } \\
\text { et al. [18] }\end{array}$ \\
\hline SI & $\begin{array}{l}\text { SI1 } \\
\text { SI2 } \\
\text { SI3 } \\
\text { SI4 }\end{array}$ & $\begin{array}{l}\text { If relatives and friends around me are taking driverless buses, I will follow along } \\
\text { If colleagues around me are taking driverless buses, I will follow along } \\
\text { Propaganda and guidance from the media will convince me to take the driverless bus } \\
\text { Taking the driverless bus will give me more conversation starters in social activities, } \\
\text { thereby enhancing my social image }\end{array}$ & $\begin{array}{c}\text { Thompson et al. [38] and } \\
\text { Ajzen [20] }\end{array}$ \\
\hline FC & $\begin{array}{l}\text { FC1 } \\
\text { FC2 } \\
\text { FC3 }\end{array}$ & $\begin{array}{l}\text { Driverless buses have received much policy support } \\
\text { Related management technologies can support driverless bus operations } \\
\text { I already have the knowledge needed to ride a driverless bus }\end{array}$ & Thompso \\
\hline PI & $\begin{array}{l}\text { PI1 } \\
\text { PI2 } \\
\text { PI3 } \\
\text { PI4 }\end{array}$ & $\begin{array}{l}\text { I often pay attention to the development trend of driverless buses } \\
\text { I am willing to try new technology products and services } \\
\text { I am often the first to use emerging technology products or services among my } \\
\text { acquaintances } \\
\text { I am good at exploring and trying new things }\end{array}$ & Rogers [39] \\
\hline $\mathrm{PR}$ & $\begin{array}{l}\text { PR1 } \\
\text { PR2 } \\
\text { PR3 } \\
\text { PR4 } \\
\text { PR5 } \\
\text { PR6 }\end{array}$ & $\begin{array}{l}\text { I think the speed of driverless buses is not fast enough, which will affect my travel } \\
\text { time } \\
\text { I am concerned that driverless buses will cost more than traditional buses } \\
\text { I am concerned that the functional design of driverless buses is still not perfect today } \\
\text { I am concerned about being persecuted by others in the driverless buses } \\
\text { I am concerned that the safety performance of driverless buses is not guaranteed } \\
\text { I am concerned that driverless buses will conflict and interfere with human-driven } \\
\text { vehicles }\end{array}$ & $\begin{array}{c}\text { Zhang et al. [16] and Zmud } \\
\text { et al. [45] }\end{array}$ \\
\hline AI & $\begin{array}{l}\text { AI1 } \\
\text { AI2 } \\
\text { AI3 }\end{array}$ & $\begin{array}{l}\text { I will take the driverless bus when the technology is mature in the future } \\
\text { I will take driverless buses often in the future } \\
\text { I would highly recommend taking driverless buses to my relatives and friends }\end{array}$ & Davis [17] \\
\hline
\end{tabular}

SM is used to describe the relationships between each latent variable. The SEM method has been widely applied in psychology, pedagogy, sociology, and other research fields [46-48]. At the same time, to ensure the validity of the questionnaire design and the adaptability of the constructed model, the reliability and validity of the model, as well as its overall goodness of fit, need to be tested through the data obtained from the questionnaire survey. Related calculations were performed using Mplus 7.4 software.
The reliability and validity of the questionnaires were tested using the confirmatory factor analysis (CFA) method. The reliability test generally examines the internal consistency of the questionnaire measurement items, which is usually evaluated by the construct reliability (CR). The evaluation criteria (threshold) adopted by Kline and many other researchers $[44,49,50]$ are as follows: a CR value of above 0.9 is the best; $0.8-0.9$ is very good; $0.7-0.8$ is moderate; $0.5-0.7$ is acceptable. The validity test generally examines the two aspects of convergent validity and discriminant validity. 
If the factor loading coefficient of each measurement variable exceeds 0.6 , and the average variance extracted (AVE) is greater than 0.5 , the model has a good convergent validity [51]. According to the evaluation criteria proposed by Fomell and Larcker [52], if the square root of AVE of each latent variable is greater than the Pearson correlation coefficient (PCC) between this variable and the other variables, the model has good discriminant validity.

The covariance matrix of measurement variables generated by quantitative parameter estimation was tested for its closeness to the sample covariance matrix. The better the model fits, the more accurate the parameter estimation is. The model's overall goodness-of-fit indices include chi-square degree of freedom ratio ( $\chi^{2} / \mathrm{df}$, also known as standard chi-square), root mean square error of approximation (RMSEA), comparative fit index (CFI), nonnormed fit index (NNFI, also known as the Tucker-Lewis Index, TLI), and standardized root mean square residual (SRMR). Kline et al. pointed out that for a good model fit, the goodness-of-fit indices should meet the following criteria: $\chi^{2} / \mathrm{df}$ is in the range of $1-3$, CFI and TLI are greater than 0.90 , and RMSEA and SRMR are less than $0.08[44,53]$.

Since the core variables in the current model are all latent variables, which are difficult to observe directly, the average score of each measurement variable corresponding to the latent variable in each data sample was taken as the observed value of the latent variable. With these observed values as the dependent variable, and with age, gender, and education as the independent variables, a multivariate analysis of variance (ANOVA) was conducted to test whether these controlled variables had significantly different effects on the latent variables in the model $(P<0.05$ was used as the significance criterion).

\section{Results}

4.1. Measurement Model Evaluation. The CFA results of the measurement model are listed in Tables 4 and 5. The CR values of all latent variables are greater than 0.8 , indicating that the internal consistency or isomorphism between the measurement variables of the same latent variable is good. As reflected by the measurement variables, the construct (latent trait) has a good consistency, and the reliability is at the "very good" level. The factor loading coefficients of all measurement variables are greater than 0.7, and the AVE values are greater than 0.5, indicating that the measurement variables have a high degree of internal correlation, which can effectively reflect the latent traits of the latent variables. Also, the proportion of variance explained by the latent variable is much higher than that explained by the measurement error, thus indicating that the measurement model has good convergent validity. The square root of AVE value of each latent variable is all greater than the PCC value between this latent variable and the other ones, indicating that there are significant differences between the constructs of different latent variables, and the model has good discriminant validity. It can be seen that both the reliability and validity of the model have passed the test, thereby showing that the model has good internal quality.

4.2. Structural Model Evaluation. The overall goodness-of-fit test results of the model are listed in Table 6. All the
TABLE 4: Analysis results of reliability and convergent validity.

\begin{tabular}{|c|c|c|c|c|}
\hline $\begin{array}{l}\text { Latent } \\
\text { variable }\end{array}$ & Item no. & $\begin{array}{c}\text { Factor loading } \\
\text { coefficient }\end{array}$ & CR & AVE \\
\hline \multirow{3}{*}{$\mathrm{EE}$} & EE1 & 0.857 & \multirow{3}{*}{0.858} & \multirow{3}{*}{0.669} \\
\hline & EE2 & 0.811 & & \\
\hline & EE3 & 0.784 & & \\
\hline \multirow{3}{*}{ PE } & PE1 & 0.719 & \multirow{3}{*}{0.817} & \multirow{3}{*}{0.599} \\
\hline & PE2 & 0.767 & & \\
\hline & PE3 & 0.832 & & \\
\hline \multirow{4}{*}{ SI } & SI1 & 0.769 & \multirow{4}{*}{0.850} & \multirow{4}{*}{0.586} \\
\hline & SI2 & 0.775 & & \\
\hline & SI3 & 0.781 & & \\
\hline & SI4 & 0.736 & & \\
\hline \multirow{3}{*}{ FC } & FC1 & 0.722 & \multirow{3}{*}{0.802} & \multirow{3}{*}{0.575} \\
\hline & FC2 & 0.797 & & \\
\hline & FC3 & 0.753 & & \\
\hline \multirow{4}{*}{ PI } & PI1 & 0.781 & \multirow{4}{*}{0.872} & \multirow{4}{*}{0.631} \\
\hline & PI2 & 0.802 & & \\
\hline & $\mathrm{PI} 3$ & 0.730 & & \\
\hline & PI4 & 0.859 & & \\
\hline \multirow{6}{*}{ PR } & PR1 & 0.845 & \multirow{6}{*}{0.924} & \multirow{6}{*}{0.672} \\
\hline & PR2 & 0.762 & & \\
\hline & PR3 & 0.873 & & \\
\hline & PR4 & 0.767 & & \\
\hline & PR5 & 0.835 & & \\
\hline & PR6 & 0.829 & & \\
\hline \multirow{3}{*}{ AI } & AI1 & 0.847 & \multirow{3}{*}{0.874} & \multirow{3}{*}{0.698} \\
\hline & $\mathrm{AI} 2$ & 0.782 & & \\
\hline & $\mathrm{AI} 3$ & 0.875 & & \\
\hline
\end{tabular}

TABLe 5: Analysis results of discriminant validity.

\begin{tabular}{lccccccc}
\hline & EE & PE & SI & FC & PI & PR & AI \\
\hline EE & $\mathbf{0 . 8 1 8}$ & & & & & & \\
PE & 0.523 & $\mathbf{0 . 7 7 4}$ & & & & & \\
SI & 0.719 & 0.716 & $\mathbf{0 . 7 6 6}$ & & & & \\
FC & 0.431 & 0.682 & 0.373 & $\mathbf{0 . 7 5 8}$ & & & \\
PI & 0.447 & 0.640 & 0.605 & 0.634 & $\mathbf{0 . 7 9 4}$ & & \\
PR & 0.390 & 0.531 & 0.433 & 0.420 & -0.622 & $\mathbf{0 . 8 2 0}$ & \\
AI & 0.535 & 0.549 & 0.468 & 0.653 & 0.715 & -0.731 & $\mathbf{0 . 8 3 5}$ \\
CR & 0.858 & 0.817 & 0.850 & 0.802 & 0.872 & 0.924 & 0.874 \\
AVE & 0.669 & 0.599 & 0.586 & 0.575 & 0.631 & 0.672 & 0.698
\end{tabular}

Note: values on the diagonal of the coefficient matrix in the table are the square roots of the AVE values, and values in the lower triangular matrix are the PCCs between variables.

TABle 6: Test results of goodness of fit.

\begin{tabular}{lccccc}
\hline Evaluation Index & $\chi^{2} / \mathrm{df}$ & CFI & TLI & RMSEA & SRMR \\
\hline Criterion & $(1,3)$ & $>0.90$ & $>0.90$ & $<0.08$ & $<0.08$ \\
Test value & 2.49 & 0.95 & 0.93 & 0.04 & 0.05 \\
\hline
\end{tabular}

goodness-of-fit evaluation indices reached the test criteria, indicating that the model has good adaptability and external quality. The standardized path coefficient $\beta$ can reflect the magnitude of the interaction between variables. The square multiple correlation (SMC) of endogenous latent variables, namely, $R^{2}$, can reflect the explanatory power of the model. 
The standardized path analysis results of the structural model are given in Table 7 and Figure 3.

The impact of each latent variable on acceptance intention is ranked from the highest to lowest as follows: PR $(\beta=-0.82, P<0.001)$, PI $(\beta=0.71, P<0.001)$, SI $(\beta=0.65$, $P<0.001)$, PE $(\beta=0.59, P<0.001)$, EE $(\beta=0.43, P<0.01)$, and FC $(\beta=0.30, P<0.05)$. All latent variables have shown a significant impact on the acceptance intention with a confidence interval of $95 \%$ (corresponding to $P<0.05$ ). PI has also exhibited a significant impact on $\mathrm{PR}(\beta=-0.62$, $P<0.001)$. The only exception is that SI did not present a significant impact on PI $(\beta=0.33, P>0.05)$. Therefore, among the research hypotheses about the latent variables, $\mathrm{H} 1-\mathrm{H} 6$ and $\mathrm{H} 8$ are valid, but $\mathrm{H} 7$ is invalid. In the model, the proportion of variance in PI that can be explained by SI is $11 \%\left(R^{2}=0.11\right)$; the proportion of variance in PR that can be explained by PI is $35 \%\left(R^{2}=0.35\right)$; the proportion of variance in acceptance intention (AI) that can be explained by all the other variables is $48 \%\left(R^{2}=0.48\right)$. The evaluation criteria of $R^{2}$ pointed out by Marcoulides [54] are as follows: $R^{2}$ lower than 0.19 indicates that the explanatory power is unacceptable; $0.19-0.33$ indicates that the explanatory power is weak; $0.33-0.67$ indicates that the explanatory power is moderate; above 0.67 indicates that the explanatory power is good. In addition, the evaluation criteria proposed by Cohen et al. [55] point out that when $R^{2}$ reaches 0.40 , the theoretical model is considered as having good explanatory power. Following the evaluation criteria proposed by Marcoulides [54] and Cohen et al. [55], it can be inferred that the theoretical model has good explanatory power for acceptance intention.

4.3. Controlled Variable Analysis. The results of ANOVA for the moderating effect of controlled variables on each latent variable are given in Table 8. It can be seen that gender has a significant moderating effect on the three influencing factors of EE, SI, and PR; age has a significant moderating effect on the four influencing factors of EE, SI, FC, PI, PR, and AI; education level has a significant moderating effect on the four influencing factors of PE, FC, PI, PR and AI. Overall, the three controlled variables of gender, age, and education level have significantly different effects on the latent variables of the model; thus, the research hypothesis about controlled variables (H9) is valid.

\section{Discussion}

According to the empirical analysis results, except for research hypothesis $\mathrm{H} 7$, the other research hypotheses have all been verified as valid. The PI and PR variables newly added in this study are shown to have a significant impact on the acceptance intention, even greater than the impacts of the other variables in UTAUT. Also, the impacts of model variables on the acceptance intention are similar to those observed in other countries or regions in the field of technology acceptance and, even more specifically, in the field of autonomous driving technology acceptance; however, there are also some differences.
5.1. Impacts of $E E$ and $P E$ on Acceptance Intention. It is found from the empirical study that both $\mathrm{EE}$ and $\mathrm{PE}$ have a significantly positive impact on acceptance intention. However, in some studies on the acceptance behavior of automated driving in other countries or regions, such as Germany and France, EE showed no decisive impact on acceptance intention $[33,56]$. In the current study, although the impact of $\mathrm{EE}$ on acceptance intention is found to be small, it cannot be ignored. Only when the public believes that it is convenient to travel with driverless buses, and the facilities and equipment in the buses are easy to operate and effortless, will they be willing to accept the use of driverless buses. In fact, a concept similar to EE is PEOU in TAM. In a survey conducted by Zhang et al. [16] in Shenzhen, China, the impact of PEOU on AV acceptance has also been demonstrated, indicating that the Chinese public might be more concerned about the ease/difficulty of using driverless buses. On the other hand, PE is equivalent to PU in TAM. Only when the public believes that driverless buses have significant benefits in improving their work efficiency and quality of life, will they be willing to accept driverless buses. The impact of PE on acceptance intention observed in this study can be mutually supported by the results of relevant investigations and research conducted in Australia and Greece by Kaur and Rampersad [35] and Panagiotopoulos and Dimitrakopoulos [25], respectively.

5.2. Impacts of SI and FC on Acceptance Intention. Similar to the results obtained in other countries or regions $[25,57]$, SI has a significantly positive impact on acceptance intention. That is, when there is someone (influencer) who can significantly influence an individual's decision-making process, he/she will present a stronger acceptance intention if the influencer thinks that he/she should use driverless buses. In China, the composition of personal social relations is relatively complex, and an individual's behaviors are often susceptible to the influences of people or organizations closely related to them. If the information and messages about driverless buses passed around by acquaintances or organizations are positive, the possibility that he/she will understand and accept driverless buses will increase; otherwise, he/she will be likely to develop a negative stereotype towards driverless buses and believe that traveling by driverless buses is not worth considering or choosing. The impact of FC on acceptance intention is the weakest but does exist, which is similar to the research result of technology acceptance behavior reported by Venkatesh et al. [58]. Since the driverless bus is an emerging technology and has not been widely used in China, the public has little understanding of the relevant policy support, which could be the main reason for the relatively weak impact of FC on acceptance intention.

5.3. Impacts of PI and PR on Acceptance Intention. The newly added variable PI showed the second greatest impact on the acceptance intention of driverless buses, only lower than PR. This observation indicates that PI plays a vital role in affecting acceptance intention; that is, the stronger the PI is, 
TABLE 7: Standardized path analysis results of the structural model.

\begin{tabular}{|c|c|c|c|c|c|c|}
\hline Hypotheses & Standardized path coefficients & $\mathrm{CR}$ & $P$ & Significance & Hypothesis test result & $R^{2}$ \\
\hline $\mathrm{H} 1: \mathrm{EE} \longrightarrow \mathrm{AI}$ & 0.43 & 5.19 & $* *$ & Significant & H1 valid & \multirow{6}{*}{ AI: 0.48} \\
\hline $\mathrm{H} 2: \mathrm{PE} \longrightarrow \mathrm{AI}$ & 0.59 & 6.61 & $* * *$ & Significant & $\mathrm{H} 2$ valid & \\
\hline $\mathrm{H} 3: \mathrm{SI} \longrightarrow \mathrm{AI}$ & 0.65 & 7.36 & $* * *$ & Significant & H3 valid & \\
\hline $\mathrm{H} 4: \mathrm{FC} \longrightarrow \mathrm{AI}$ & 0.30 & 4.71 & $*$ & Significant & H4 valid & \\
\hline $\mathrm{H} 5: \mathrm{PI} \longrightarrow \mathrm{AI}$ & 0.71 & 10.05 & $* * *$ & Significant & H5 valid & \\
\hline H6: $\mathrm{PR} \longrightarrow \mathrm{AI}$ & -0.82 & -12.38 & $* * *$ & Significant & H6 valid & \\
\hline $\mathrm{H} 7: \mathrm{SI} \longrightarrow \mathrm{PI}$ & 0.33 & 1.52 & 0.11 & Insignificant & H7 invalid & PI: 0.11 \\
\hline $\mathrm{H} 8: \mathrm{PI} \longrightarrow \mathrm{PR}$ & -0.62 & -6.97 & $* * *$ & Significant & H8 valid & PR: 0.35 \\
\hline
\end{tabular}

Note: $\mathrm{CR}$ is the critical ratio, and a CR value greater than 1.96 indicates a significance level of 0.05 has been reached. ${ }^{* * *} P<0.001,{ }^{* *} P<0.01$, and ${ }^{*} P<0.05$.

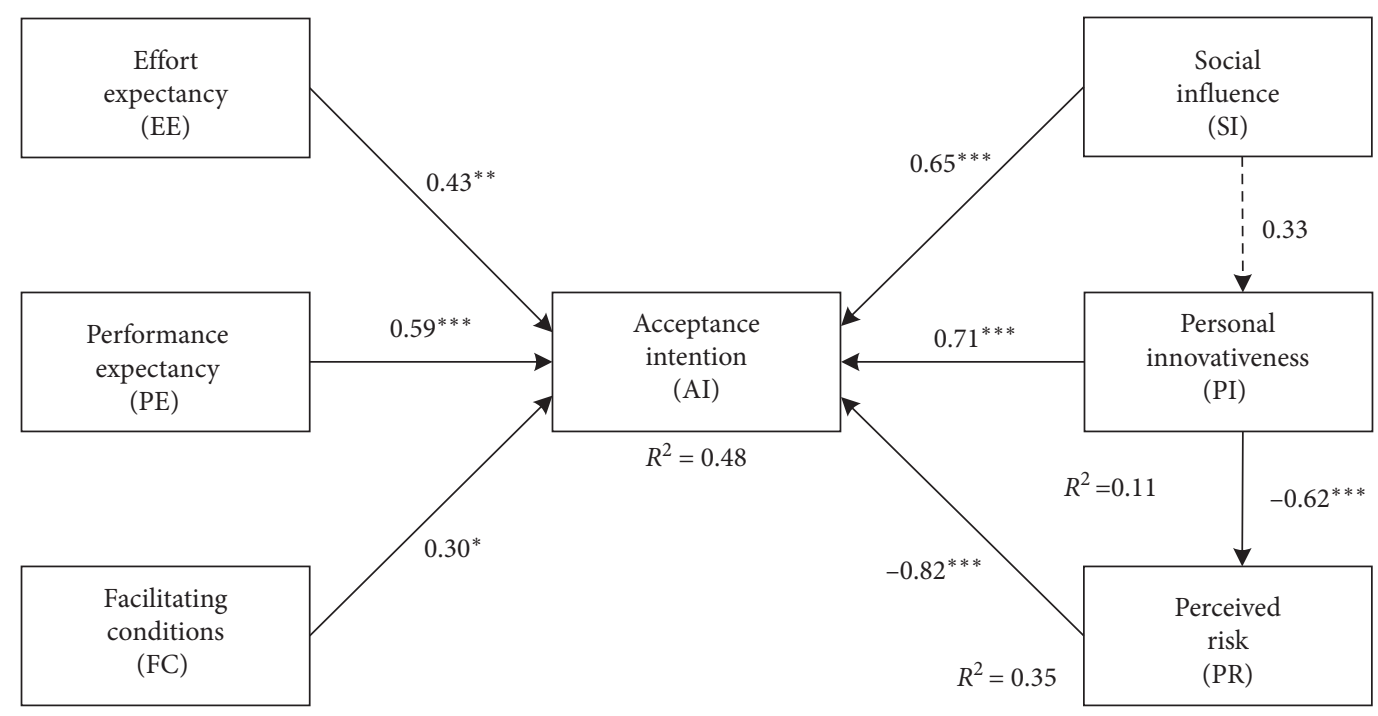

Figure 3: Analysis results of the structural model. Note: the solid arrows represent the paths with significant impacts, and the dotted arrow represents the path with insignificant impact. ${ }^{* * *} P<0.001,{ }^{* *} P<0.01$, and ${ }^{*} P<0.05$.

TABle 8: Results of ANOVA (P value).

\begin{tabular}{|c|c|c|c|c|c|c|c|}
\hline Controlled variables & $\mathrm{EE}$ & $\mathrm{PE}$ & SI & FC & PI & PR & AI \\
\hline Gender & $0.039^{*}$ & - & $0.043^{*}$ & - & - & $0.004^{* *}$ & - \\
\hline Age & $0.045^{*}$ & - & $0.036^{*}$ & $0.022^{*}$ & $0.000^{* * *}$ & $0.000^{* * *}$ & $0.001^{* *}$ \\
\hline Education level & - & $0.008^{* *}$ & - & $0.043^{*}$ & $0.002^{* *}$ & $0.020^{*}$ & $0.036^{*}$ \\
\hline
\end{tabular}

Note: if the test $P$ value is greater than 0.05 , the moderating effect is not significant; if the $P$ value is lower than 0.05 , the moderating effect is significant. ${ }^{* * *} P<0.001,{ }^{* *} P<0.01$, and ${ }^{*} P<0.05$.

the stronger the acceptance and sensitivity to emerging technologies an individual would possess, and the stronger his/her acceptance intention will be. In the studies of Jackson et al. [59] and Turan et al. [60], it has also been pointed out that PI should be regarded as one of the core influencing factors for technology acceptance in combination with the DIT theory. The impact of PR on acceptance intention ranks first in this study, indicating that respondents in Chongqing, China, are especially concerned about the safety of driverless buses. The greater an individual's PR is, the more likely he/ she will express a negative acceptance intention. This observation could be related to the more conservative and cautious personality traits of some Chinese people. In the studies of Piao et al. [61] and Nazari et al. [62], it has also been emphasized that perception of lower risk is a critical factor affecting the public acceptance of AVs. In the investigations and research conducted by Zmud et al. [45] and Menon et al. [63] in Texas and Florida in the USA, it has also been found that PR has a negative impact on the acceptance intention of AVs. In the study conducted by Liu et al. [14] in Tianjin, China, it was pointed out that the impact of PR on the acceptance intention of AVs does exist but is not strong. It is explained that this phenomenon could be due to the public's insufficient awareness about the risks of AVs. At the same time, in the current study, PI was also found to have a relatively significant negative impact on PR; that is, the stronger an individual's PI is, the more optimistic he/she will be in considering the risk factors in the environment, thereby presenting a relatively weaker ability to perceive risks. 
5.4. Effects of Age, Gender, and Education Level on the Model Variables. Through the ANOVA, it is concluded that the effects of demographic attributes-such as age, gender, and education level-on the core latent variables in the constructed model are significantly different; that is, they have a moderating effect on the influence relationships in the model. Many studies have argued that the effects of these demographic attribute variables on the UTAUT model are not obvious or have been weakening gradually $[16,32]$. However, the current study finds that the effects of these demographic attribute variables on the model variables cannot be ignored. This conclusion coincides with the findings of Venkatesh et al. [58] and Bansal et al. [37] in their studies in Arkansas and Texas, USA. Among the demographic attributes, age and education level have exhibited an especially obvious effect on the public's acceptance intention of driverless buses.

\section{Conclusions}

The purpose of this study is to explore the influencing factors that affect the public's acceptance intention of driverless buses as well as the relationships between the various factors. The research results can be expected to provide preliminary references for research in this field. A driverless bus acceptance analysis model was constructed by extending the UTAUT model. The SEM method was applied to describe the measurement relationship between latent variables and measurement variables, as well as the structural relationships between the latent variables. The data obtained from the actual survey of respondents in Chongqing, China, were used to verify the mutual influence relationships in the model quantitatively. In the current study, it is found that EE, PE, SI, FC, PI, and PR all have a significant impact on acceptance intention; also, the impacts of the two newly added variables-PR and PI-on the acceptance intention for driverless buses are especially prominent. It can be considered that this extended model has good applicability for the research of acceptance intention for driverless buses.

This study has two levels of significance in terms of theoretical enlightenment and practical application reference. At the theoretical level, this study extends the integrated technology acceptance model and incorporates new variables that can characterize the features of driverless buses. An empirical basis has been provided for the effective combination of the DIT theory, perceived risk theory, and UTAUT model. The theoretical analysis methods have been enriched in the research field of technology acceptance. At the practical application level, this study explored the influencing factors that could affect the public's acceptance intention of driverless buses. An understanding of these factors will be beneficial for analyzing the market, thereby providing directions for driverless bus manufacturers and policymakers in future technology research and development as well as functional design. The research outcomes can also provide objective reference opinions for the government to issue management policies for driverless buses. For example, it is found in this study that PR is the most important influencing factor for acceptance intention, so the functional design of driverless buses should improve their safety performance to reduce the public's concerns about the riding time, cost, and personal safety en route.

However, this study inevitably has limitations that need to be resolved. First, this study analyzed the acceptance BIs for driverless buses, which could not represent actual behaviors completely because driverless public transportation has not yet been widely put into market application in China, and most respondents did not have actual use experience. Therefore, their acceptance behaviors can only be explored indirectly through BIs, which will more or less lead to some deviations. Once driverless bus technology has become more mature, further research can be carried out according to the actual use behaviors of the public. Second, the explanatory power of the current research model for the acceptance intention of driverless buses is $48 \%$, which indicates that the model has not fully captured the influencing factors for the public acceptance intention. Whether other influencing factors in the research field of technology acceptance (such as HM, trust level, and environmental awareness) would significantly affect acceptance intention still requires further exploration. Third, the effects of demographic attributes (such as gender, age, and education level) of respondents on acceptance intention are found to be significantly different in this study, but many other studies suggest the opposite; therefore, more follow-up research should be conducted to verify this observation.

\section{Data Availability}

The data used to support the findings of this study are available from the corresponding author upon request.

\section{Conflicts of Interest}

The authors declare that there are no conflicts of interest regarding the publication of this paper.

\section{Acknowledgments}

This research was funded by the Western Project of the National Social Science Fund of China (grant no. 17XGL009).

\section{Supplementary Materials}

Questionnaire on public acceptance of driverless buses. Part 1: personal information. Part 2: a measurement scale for public's subjective perceptions of driverless buses. (Supplementary Materials)

\section{References}

[1] SAE International, "Taxonomy and definitions for terms related to on-road motor vehicle automated driving systems," Report No, J3016_201806, SAE International, Warrendale, PA, USA, 2018.

[2] D. J. Fagnant and K. Kockelman, "Preparing a nation for autonomous vehicles: opportunities, barriers and policy recommendations," Transportation Research Part A: Policy and Practice, vol. 77, pp. 167-181, 2015. 
[3] I. Y. Noy, D. Shinar, and W. J. Horrey, "Automated driving: safety blind spots," Safety Science, vol. 102, pp. 68-78, 2018.

[4] Z. Xu, K. Zhang, H. Min, Z. Wang, X. Zhao, and P. Liu, "What drives people to accept automated vehicles? findings from a field experiment," Transportation Research Part C: Emerging Technologies, vol. 95, pp. 320-334, 2018.

[5] B. Schoettle and M. Sivak, A Survey of Public Opinion about Autonomous and Self-Driving Vehicles in the U.S., the U.K., and Australia, Transportation Research Institute: University of Michigan, Ann Arbor, MI, USA, 2014.

[6] M. Kyriakidis, R. Happee, and J. C. F. De Winter, "Public opinion on automated driving: results of an international questionnaire among 5000 respondents," Transportation Research Part F: Traffic Psychology and Behaviour, vol. 32, pp. 127-140, 2015.

[7] C. Tennant, S. Stares, and S. Howard, "Public discomfort at the prospect of autonomous vehicles: building on previous surveys to measure attitudes in 11 countries," Transportation Research Part F: Traffic Psychology and Behaviour, vol. 64, pp. 98-118, 2019.

[8] W. Payre, J. Cestac, and P. Delhomme, "Intention to use a fully automated car: attitudes and a priori acceptability," Transportation Research Part F: Traffic Psychology and Behaviour, vol. 27, pp. 252-263, 2014.

[9] C. Hohenberger, M. Spörrle, and I. M. Welpe, "How and why do men and women differ in their willingness to use automated cars? the influence of emotions across different age groups," Transportation Research Part A: Policy and Practice, vol. 94, pp. 374-385, 2016.

[10] C. J. Haboucha, R. Ishaq, and Y. Shiftan, "User preferences regarding autonomous vehicles," Transportation Research Part C: Emerging Technologies, vol. 78, pp. 37-49, 2017.

[11] S. Nordhoff, J. de Winter, R. Madigan, N. Merat, B. van Arem, and R. Happee, "User acceptance of automated shuttles in Berlin-Schöneberg: a questionnaire study," Transportation Research Part F: Traffic Psychology and Behaviour, vol. 58, pp. 843-854, 2018.

[12] A. O. Salonen, "Passenger's subjective traffic safety, in-vehicle security and emergency management in the driverless shuttle bus in Finland," Transport Policy, vol. 61, no. 1, pp. 106-110, 2018.

[13] C. Bernhard, D. Oberfeld, C. Hoffmann, D. Weismüller, and H. Hecht, "User acceptance of automated public transport: valence of an autonomous minibus experience," Transportation Research Part F: Traffic Psychology and Behaviour, vol. 70, pp. 109-123, 2020.

[14] P. Liu, R. Yang, and Z. Xu, "Public acceptance of fully automated driving: effects of social trust and risk/benefit perceptionsffects of social trust and risk/benefit perceptions," Risk Analysis, vol. 39, no. 2, pp. 326-341, 2019.

[15] J. Wu, H. Liao, J.-W. Wang, and T. Chen, "The role of environmental concern in the public acceptance of autonomous electric vehicles: a survey from China," Transportation Research Part F: Traffic Psychology and Behaviour, vol. 60, pp. 37-46, 2019.

[16] T. Zhang, D. Tao, X. Qu, X. Zhang, R. Lin, and W. Zhang, “The roles of initial trust and perceived risk in public's acceptance of automated vehicles," Transportation Research Part C: Emerging Technologies, vol. 98, pp. 207-220, 2019.

[17] F. D. Davis, "Perceived usefulness, perceived ease of use, and user acceptance of information technology," MIS Quarterly, vol. 13, no. 3, pp. 319-340, 1989.

[18] V. Venkatesh, M. G. Morris, G. B. Davis, and F. D. Davis, "User acceptance of information technology: toward a unified view,” MIS Quarterly, vol. 27, no. 3, pp. 425-478, 2003.
[19] M. Fishbein and I. Ajzen, "Belief, attitude, intention and behaviour: an introduction to theory and research," Philosophy \& Rhetoric, vol. 41, no. 4, pp. 842-844, 1980.

[20] I. Ajzen, "The theory of planned behavior," Organizational Behavior and Human Decision Processes, vol. 50, no. 2, pp. 179-211, 1991.

[21] V. Venkatesh and F. D. Davis, "A theoretical extension of the technology acceptance model: four longitudinal field studies," Management Science, vol. 46, no. 2, pp. 186-204, 2000.

[22] J. K. Choi and Y. G. Ji, "Investigating the importance of trust on adopting an autonomous vehicle," International Journal of Human-Computer Interaction, vol. 31, no. 10, pp. 692-702, 2015.

[23] T. Zhang, D. Tao, X. Qu et al., "Automated vehicle acceptance in China: social influence and initial trust are key determinants," Transportation Research Part C: Emerging Technologies, vol. 112, pp. 220-233, 2020.

[24] S. R. Winter, S. Rice, R. Mehta et al., "Do Americans differ in their willingness to ride in a driverless bus?," Journal of Unmanned Vehicle Systems, vol. 6, no. 4, pp. 267-278, 2018.

[25] I. Panagiotopoulos and G. Dimitrakopoulos, "An empirical investigation on consumers' intentions towards autonomous driving," Transportation Research Part C: Emerging Technologies, vol. 95, pp. 773-784, 2018.

[26] J. Lee, D. Lee, Y. Park, S. Lee, and T. Ha, "Autonomous vehicles can be shared, but a feeling of ownership is important: examination of the influential factors for intention to use autonomous vehicles," Transportation Research Part C: Emerging Technologies, vol. 107, pp. 411-422, 2019.

[27] N. Puspitasari, M. B. Firdaus, C. A. Haris, and H. J. Setyadi, "An application of the UTAUT model for analysis of adoption of integrated license service information system," Procedia Computer Science, vol. 161, pp. 57-65, 2019.

[28] R. Hoque and G. Sorwar, "Understanding factors influencing the adoption of mHealth by the elderly: an extension of the UTAUT model," International Journal of Medical Informatics, vol. 101, pp. 75-84, 2017.

[29] S. Chauhan and M. Jaiswal, "Determinants of acceptance of ERP software training in business schools: empirical investigation using UTAUT model," The International Journal of Management Education, vol. 14, no. 3, pp. 248-262, 2016.

[30] J. Khalilzadeh, A. B. Ozturk, and A. Bilgihan, "Security-related factors in extended UTAUT model for NFC based mobile payment in the restaurant industry," Computers in Human Behavior, vol. 70, pp. 460-474, 2017.

[31] S. Sarosa, "The role of brand reputation and perceived enjoyment in accepting compulsory device's usage: extending UTAUT," Procedia Computer Science, vol. 161, pp. 115-122, 2019.

[32] R. Madigan, T. Louw, M. Dziennus et al., "Acceptance of automated road transport systems (ARTS): an adaptation of the UTAUT model," Transportation Research Procedia, vol. 14, pp. 2217-2226, 2016.

[33] R. Madigan, T. Louw, M. Wilbrink, A. Schieben, and N. Merat, "What influences the decision to use automated public transport? using UTAUT to understand public acceptance of automated road transport systems," Transportation Research Part F: Traffic Psychology and Behaviour, vol. 50, pp. 55-64, 2017.

[34] M. M. Rahman, M. F. Lesch, W. J. Horrey, and L. Strawderman, "Assessing the utility of TAM, TPB, and UTAUT for advanced driver assistance systems," Accident Analysis \& Prevention, vol. 108, pp. 361-373, 2017. 
[35] K. Kaur and G. Rampersad, "Trust in driverless cars: investigating key factors influencing the adoption of driverless cars," Journal of Engineering and Technology Management, vol. 48, pp. 87-96, 2018.

[36] R. J. Holden and B.-T. Karsh, "The technology acceptance model: its past and its future in health care," Journal of Biomedical Informatics, vol. 43, no. 1, pp. 159-172, 2010.

[37] P. Bansal, K. M. Kockelman, and A. Singh, "Assessing public opinions of and interest in new vehicle technologies: an Austin perspective," Transportation Research Part C: Emerging Technologies, vol. 67, pp. 1-14, 2016.

[38] R. L. Thompson, C. A. Higgins, and J. M. Howell, "Personal computing: toward a conceptual model of utilization," MIS Quarterly, vol. 15, no. 1, pp. 125-143, 1991.

[39] E. M. Rogers, Diffusion of Innovations, The Free Press, New York, NY, USA, 1983.

[40] R. A. Bauer, "Consumer behavior as risk taking," in Proceedings of the 43rd American Marketing Association Conference, R. S. Hancock, Ed., American Marketing Association: CHI, Chicago, IL, USA, pp. 389-398, June 1960.

[41] J. Jacoby and L. B. Kaplan, "The components of perceived risk," Advances in Consumer Research, vol. 3, pp. 382-383, 1972.

[42] P. Bansal and K. M. Kockelman, "Forecasting Americans' long-term adoption of connected and autonomous vehicle technologies," Transportation Research Part A: Policy and Practice, vol. 95, pp. 49-63, 2017.

[43] J. J. Hoogland and A. Boomsma, "Robustness studies in covariance structure modeling," Sociological Methods \& Research, vol. 26, no. 3, pp. 329-367, 1998.

[44] R. B. Kline, Principles and Practice of Structural Equation Modeling, Guilford Press, New York, NY, USA, 2nd edition, 2005.

[45] J. P. Zmud, I. N. Sener, and J. Wagner, Consumer Acceptance and Travel Behavior Impacts of Automated Vehicles (PRC1549F), Texas A\&M Transportation Institute, Bryan, TX, USA, 2016.

[46] J. R. Priester, "The use of structural equation models in consumer psychology: a methodological dialogue on its contributions, cautions, and concerns," Journal of Consumer Psychology, vol. 20, no. 2, pp. 205-207, 2010.

[47] H. Camgoz-Akdag and S. Zaim, "Education: a comparative structural equation modeling study," Procedia-Social and Behavioral Sciences, vol. 47, pp. 874-880, 2012.

[48] F. Boccia and P. Sarnacchiaro, "Structural equation model for the evaluation of social initiatives on customer behaviour," Procedia Economics and Finance, vol. 17, pp. 211-220, 2014.

[49] R. P. Bagozzi and Y. Yi, "On the evaluation of structural equation models," Journal of the Academy of Marketing Science, vol. 16, no. 1, pp. 74-94, 1988.

[50] J. F. J. Hair, R. E. J. Anderson, R. L. Tatham, and W. C. Black, Multivariate Data Analysis, Prentice Hall, Upper Saddle River, NJ, USA, 5th edition, 1998.

[51] M. R. A. Hamid, W. Saml, and M. H. Mohmad-Sldek, "Discriminant validity assessment: use of Fornell \& Larcker criterion versus HIMT criterion," Journal of Physics: Conference Series, vol. 890, Article ID 012163, 2017.

[52] C. Fomell and D. F. Larcker, "Evaluating structural equation models with unobservable variables and measurement error," Journal of Marketing Research, vol. 18, no. 1, pp. 39-50, 1981.

[53] L. T. Hu and P. M. Bentler, "Cutoff criteria for fit indexes in covariance structure analysis: conventional criteria versus new alternatives," Structural Equation Modeling: A Multidisciplinary Journal, vol. 6, no. 1, pp. 1-55, 1999.
[54] G. Marcoulides, Modern Methods for Business Research, Psychology Press, New York, NY, USA, 1998.

[55] P. Cohen, S. G. West, and L. S. Aiken, Applied Multiple Regression/Correlation Analysis for the Behavioral Sciences, Psychology Press, London, UK, 2014.

[56] E. Adell, "Acceptance of driver support systems," in Proceedings of the European Conference on Human Centred Design for Intelligent Transport Systems, J. Krems, T. Petzoldt, and M. Henning, Eds., Humanist VCE: Ifsttar-Lyon-Bron, Berlin, Germany, pp. 475-486, April 2010.

[57] J. P. Zmud and I. N. Sener, "Towards an understanding of the travel behavior impact of autonomous vehicles," Transportation Research Procedia, vol. 25, pp. 2500-2519, 2017.

[58] V. Venkatesh, J. Y. L. Thong, and X. Xu, "Consumer acceptance and use of information technology: extending the unified theory of acceptance and use of technology," MIS Quarterly, vol. 36, no. 1, pp. 157-178, 2012.

[59] J. D. Jackson, M. Y. Yi, and J. S. Park, "An empirical test of three mediation models for the relationship between personal innovativeness and user acceptance of technology," Information \& Management, vol. 50, no. 4, pp. 154-161, 2013.

[60] A. Turan, A. Ö. Tunç, and C. Zehir, "A theoretical model proposal: personal innovativeness and user involvement as antecedents of unified theory of acceptance and use of technology," Procedia-Social and Behavioral Sciences, vol. 210, pp. 43-51, 2015.

[61] J. Piao, M. Mcdonald, N. Hounsell, M. Graindorge, T. Graindorge, and N. Malhene, "Public views towards implementation of automated vehicles in urban areas," Transportation Research Procedia, vol. 14, pp. 2168-2177, 2016.

[62] F. Nazari, M. Noruzoliaee, and A. Mohammadian, "Shared versus private mobility: modeling public interest in autonomous vehicles accounting for latent attitudes," Transportation Research Part C: Emerging Technologies, vol. 97, pp. 456-477, 2018.

[63] N. Menon, A. R. Pinjari, Y. Zhang, and L. Zou, Consumer Perception and Intended Adoption of Autonomous Vehicle Technology-Findings from a University Population Survey, Transportation Research Board: WDC, Washington, DC, USA, 2016. 